\title{
Welcome to Boston
}

\author{
The best meeting we've ever had
}

On behalf of the Materials Research Society, it is a great pleasure for me to welcome you to the 1984 Fall Meeting of the MRS. This meeting promises to be the most successful in the history of the Society. Sixteen symposia on forefront topics in materials research, and the ever-popular lunchtime Symposium $\mathrm{X}$, constitute the technical program for this meeting. The quality of the program is the best that we have ever had and almost 1,000 presentations will be given in the oral and poster sessions. This meeting provides a unique opportunity for materials professionals throughout the world to gather together to discuss technical issues that confront us at the leading edge of materials technology.

\section{An Outstanding Program}

Organizing a meeting of this size requires the active participation of dozens of people. These include the

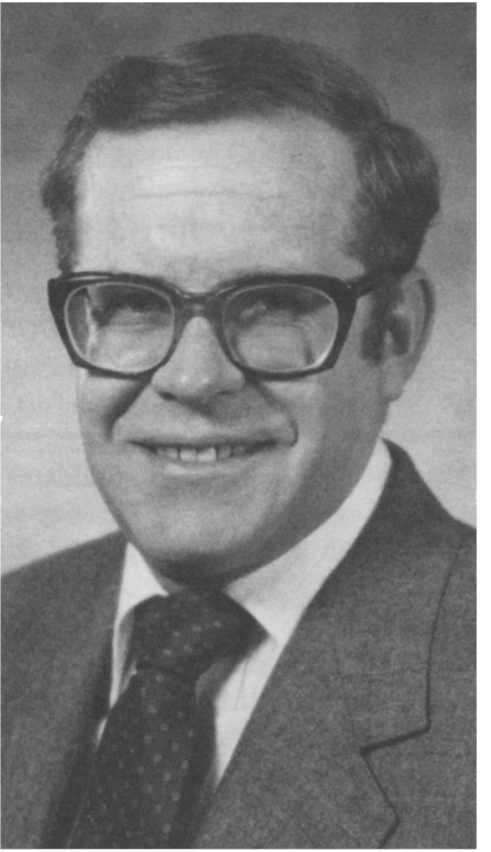

'WOODY' WHITE symposia chairpersons, the headquarters staff, the committees of the Society, and many others. All of the activity is directed and brought into focus by the meeting chairmen-Walter L. Brown, AT\&T Bell Laboratories; Jagdish Narayan, North Carolina State University, and Paul S. Peercy, Sandia National Laboratories. The scope of their accomplishments is described in this issue of the BULLETIN, and will be apparent throughout the meeting week. It is impossible to describe the magnitude of their task or the time and effort that was required to make this happen. The Society owes them an enormous debt of gratitude, for the program they and the symposia chairmen have assembled is outstanding.

The individual symposia in this meeting address topics that are at the leading edge of materials research. The symposia chairpersons have done an outstanding job in putting together the programs for these symposia. Our objective is for the symposia sponsored by the Materials Research Society to be recognized as international conferences in that topical area, bringing together technologists from many disciplines to discuss mutual problems. The programs assembled by the symposia chairmen have clearly fulfilled this objective.

\section{Expanded Range of Services}

In addition to a superb technical program, this year for the first time we are including several other activities in the Boston meeting. These include a major Equipment Show, where the latest in analytical and processing equipment will be displayed, and the services of a formal Job Placement Center. We expect these activities to contribute significantly to the quality of the meeting and to provide additional service to the members of the MRS. Both of these activities are being organized for us by the American Institute of Physics. The opportunity to utilize services provided by the AIP is available to us because the MRS is an Affiliated Society of the AIP. Without the expertise and guidance of the AIP, it would have been impossible to include these activities in the Boston meeting at this time.

MRS meetings provide a unique opportunity for materials professionals throughout the world to gather together to discuss mutual problems and interests. These meetings are the most intensive information-sharing events available to members of our profession. We expect the approximately 2,000 participants in this meeting to come from 40 counties. This provides an unparalleled opportunity for participants to renew old acquaintances, establish new friendships, and discuss problems of common interest with members of our profession from all over the world. This opportunity for human interaction is one of the most important opportunities provided by the MRS meetings, and it contributes substantially to the quality of the meeting.

\section{The Society's Transformation}

I urge you to participate to the fullest extent possible in the meeting activities this week. I urge you also to take the opportunity to actively participate in the Materials Research Society. Ours is a young, very dynamic and growing Society. The programs and objectives of the MRS are constantly being reevaluated to ensure that they are responsive to the ever-changing needs of the materials research community. The Society has undergone an enormous transformation during the past year. Our membership has increased by $60 \%$, we have instituted a Spring Meeting on the West Coast, a permanent Headquarters Office has been formed, we have taken over the responsibility for producing and marketing the MRS Conference PROCEEDINGS Series, we have begun to upgrade the BulletiN, our first Local Chapter was formed and there is renewed interest in the formation of Student Chapters, and we have instituted new activities in the Fall Meeting. All of this has been accomplished because dozens of individual members were willing to devote the time and effort necessary to make things happen. The MRS has no established bureaucracy. Things get done because individual members do them. The opportunity to participate in activities that determine the programs, directions, and the future of the Society is available to all members. Take advantage of this opportunity and you will enjoy comradeship with some of the finest scientists and engineers in the world. You will also help to shape the future of the Materials Research Society as it responds to the needs of the world community of materials research professionals.

\section{C.W. "WOODY" WHITE President}

